\title{
Non-spherocytic hemolytic anemia due to hexokinase deficiency
}

INSERM

\section{Source}

INSERM. (1999). Orphanet: an online rare disease and orphan drug data base. Nonspherocytic hemolytic anemia due to hexokinase deficiency. ORPHA:90031

Nonspherocytic haemolytic anaemia due to hexokinase deficiency is characterised by severe hemolysis, appearing in infancy. Seventeen affected families have been reported so far. Transmission is autosomal recessive. Mutations have been described in HK1, the gene that encodes red blood cell-specific hexokinase-R. 